\title{
Social Perceptions of Breast Cancer by Women Still Undergoing or Having Completed Therapy: a Qualitative Study
}

\author{
Gulengul Mermer ${ }^{1 *}$, Aylin Nazlı², Esin Ceber ${ }^{3}$
}

\begin{abstract}
Background: Diagnosis and treatment of breast cancer is a crisis situation which effects women's lives physically, socially and spiritually. Investigating women's perceptions of this disease is crucially important for treatment decisions. We therefore determined social perceptions and interpretations of women diagnosed with breast cancer during therapy and in the post-treatment period. Materials and Methods: In the study, focus group and in-depth interviews were made with women still undergoing or having completed breast cancer treatment. Some 25 women were included in the research. Content analysis was used in the analysis of the qualitative data obtained after the focus group and in-depth interviews. Results: Some of the women demonstrated positive perceptions towards accepting the disease, whereas others had emotions such as rebellion and anger. The loss of a breast is important with different interpretations. Conclusions: Women's acceptance or rebellion against the disease varies within their social interpretations after the treatment, as at the stage of diagnosis/treatment. All stages of breast cancer negatively affect the social life of the affected individual as much as her body. Nurses assume crucial roles in coping with these negative effects. Thus, it is necessary to know, and sociologically interpret, what is indicated by the information on what the negative effects concerning the disease are and how they are interpreted.
\end{abstract}

Keywords: Qualitative study - focus group - breast cancer - social perception - interpretations - Turkey

Asian Pac J Cancer Prev, 17 (2), 503-510

\section{Introduction}

Breast cancer is an important and common public health problem that might cause mortalities. However, in the case of early diagnosis, there is a chance of total recovery (Guler and Akın, 2006; WHO 2015). What makes breast cancer distinctive from the other female cancer types is that it can be diagnosed at an early stage and gives quick responses to early diagnosis. The chance of survival is high with early diagnosis (Guler and Akın, 2006; Tuncer, 2007; WHO 2015).

There are qualitative investigations based on focus group or in-depth interviews about women's responses to, perception of, and ideas about breast cancer (Karbani et al., 2011; Kim et al., 2012; Rastad et al., 2012; Fouladi et al., 2014). Focusing on family and environment support and self-care and alternative medicine, these investigations explored the experiences of cancer and developed suggestions on treatment processes ( Ferrel et al., 1997; Rees and Bath, 2001; Lamyian et al., 2007; Gurm et al., 2008). The focus group interviews conducted with the women under risk, the women already diagnosed with breast cancer, and the women under treatment or with an already completed treatment process elaborated on the women's perception of breast cancer (Gall and Cornblat, 2002; Minnesota International Health Volunteers, 2006; Mellon et al., 2007; Peek et al., 2007; Oxlad et al., 2008). There are also other studies which made use of qualitative methods and addressed conditions and perception of breast cancer (Webb, 2002; Henderson et al., 2003; Gonzalez and Lengacher, 2007; Howard et al., 2007; Bakos et al., 2008; Loerzel et al., 2008; Chung et al., 2009). However, in Turkey, little research has been made on women's perception of breast cancer based on qualitative research that aims to collect in-depth information (Nazl1, 2008; Nurdan 2009).

The main purpose of this study is to show that the disease has not only medical content but also social content. Besides being a medical case with its medical content, cancer involves social content as well. In this study, it was aimed to determine the social content with respect to breast cancer on the basis of social perception and interpretations. Thus, the study aimed to determine the social perception and interpretations in the diagnosis/

${ }^{1}$ Ege University Faculty of Nursing, Public Health Nursing Department, ${ }^{2}$ Ege University Faculty of Letters, Department of Sociology, ${ }^{3}$ Ege University Izmir Ataturk School of Health, Department of Midwifery, Bornova, Izmir, Turkey, Izmir, Turkey *For correspondence: gulengul.s.mermer@ege.edu.tr 
treatment process by two female patient groups diagnosed with breast cancer/still undergoing breast cancer treatment and with completed breast cancer treatment. It was thought that these qualitative data would be influential in determining the social dimensions of the health services and social support programs with which the women still undergoing breast cancer treatment and the women with completed breast cancer treatment would be provided.

\section{Materials and Methods}

\section{Design}

This research was a descriptive investigation based on qualitative methods, namely focus group and in-depth interviews. In this qualitative research, we collected indepth and multi-dimensional information on women's experiences of breast cancer.

\section{Setting and participants}

The research was divided into two different interview groups. The groups consisted of the women who came for examination to two polyclinics at Izmir Ataturk Training and Research Hospital ( $\mathrm{n}=25$ women). When determining the social perception and interpretations of breast cancer, the first group was composed of the women diagnosed with breast cancer and still undergoing treatment particularly in order for the medical and social stimuli at the treatment stage not to lose their influence. The number of women in the group was specified as 9, for the treatment process was substantially challenging and the resulting forms of social perception had common points.

The requirement of experiencing the entire treatment process of the disease was also taken into consideration when determining the social interpretations of the disease. Therefore, the second group comprised the women whose treatment had been completed. The number of women in the second group was 16 as determining the social interpretations of the different subdimensions of the disease process and reaching common points entailed considerable qualitative data.

Criterion sampling, one of the techniques of Purposive sampling, was used as a qualitative sampling technique in the research. Being a woman, having been diagnosed with breast cancer, the continuation of treatment, the completion of treatment and having undergone mastectomy were determined as the basic criteria to set up the sampling.

\section{Procedure}

Of the women who agreed to participate in the study after they had been told the purpose of the research, the women diagnosed with breast cancer and still undergoing treatment were included in the first group and evaluated, while the women whose breast cancer treatment had been completed were included in the second group and evaluated. Due to the hard treatment conditions and the low probability of meeting, a single-session focus group interview was made with the 9 women under treatment who constituted the first group. The women in the second group with completed treatment were reached by telephone and an appointment was made with them.
Face-to-face in-depth interviews were made with this group when they came to the hospital for their control. The in-depth interview technique allowed obtaining more detailed data when determining the social perception and interpretations of the disease process by this group that had completed the diagnosis and treatment processes of the disease with a wide variety of experiences.

\section{Instruments and Data collection}

First of all, we asked our participants to fill out the form entitled "A questionnaire on the descriptive characteristics of the women." This questionnaire consisted of questions on participants' socio-demographic characteristics and descriptive information on their cancer experiences. The data were collected with qualitative methods, more specifically, through focus group and in-depth interviews. A semi-structured interview form was used in the focus group and in-depth interviews. The questions were elaborated according to the course of the interviews. The open-ended interview questions were organized under 4 headings: 1 . The diagnosis stage of breast cancer, 2 . The treatment stage of breast cancer, 3 . Support by the family and the social environment, and 4. Breast cancer support and therapy groups.

The first group consisted of the women who were still under treatment. The interviews with this group lasted for 90 minutes. We thought that these interviews had lasted longer because the women had had a lot of experience about the treatment processes.

The second group comprised the women with completed treatment who returned to their normal lives. The in-depth interviews lasted for 60 minutes on average.

\section{Ethical considerations}

In order to collect information on the women who participated, we obtained a written consent from the Medical Superintendent of Izmir Ataturk Training and Research Hospital. We paid special attention to the confidentiality of personal information of the participants. Instead of writing their names down, we only used their initials. We obtained written consents from all participants. The consent form informed the participants about the confidentiality of the research and their rights. In the consent form, we also informed the participants about the use of voice recording. We indicated that all interviews would be recorded with a voice recorder and remain confidential. We also stated that the voice records would only be used as part of this research. After we had informed the participants about our use of voice recording, we asked for their written and oral consent. We left the voice recorder on the coffee table in the interview room. We told the participants that in case of inconvenience, we would delete the records. However, none of the participants had such a demand.

\section{Data analysis}

According to the descriptive characteristics of the participants, we carried out quantity and percentage distributions. A voice recorder recorded the interviews. All the records were listened to and transcribed into a Word document by the researchers. The contents of the data were saved as a Word document. The technique of 
Social Perceptions of Breast Cancer by Women Undergoing or Having Completed Treatment: a Qualitative Study

content analysis was used in data analysis. In the analysis, the NVivo 10 program was utilized for computer-aided qualitative data analysis. The qualitative data were loaded into the program. In the analysis, coding was performed according to the concepts extracted from the qualitative data. The qualitative data in the documents were read carefully, and key concepts were coded. Later on, from these codes, categories were generated according to the similarities and differences between them. It was seen that the categories included the disease process. Diagnosis, Treatment, Support by the family and the social environment and Breast cancer support/therapy groups were the basic categories of analysis that were generated. The qualitative data were coded on the basis of the concepts and the categories by the help of the NVivo 10 program. In this analysis, it was aimed to organize and interpret the qualitative data by means of specific categories and concepts. The coding of the qualitative data in the documents was performed according to the open coding technique (Strauss and Corbin, 1998; Strauss, 2003). In the analysis, the 4 basic stages of the disease process specified for the questions (diagnosis, treatment, support by the family and the social environment, and breast cancer support/therapy groups) were determined as the basic categories of analysis. The qualitative data in each category were read carefully; short notes were taken down; and then key concepts were generated. The qualitative data were organized according to the list of key codes under the four basic categories they belonged to. The data were interpreted within the framework of the four basic categories. The differences in the data of two patient groups were considered in each category, and the presentation and interpretation of the data were carried out on the basis of the two groups. As a result of the analysis, findings were obtained regarding the social perception and interpretations of the diagnosis of breast cancer, its treatment stage, the family/the social environment, and support/therapy groups.

\section{Results}

\section{Descriptive characteristics of the participants}

It was found out that of the women still undergoing treatment, $77.8 \%$ were aged fifty years and over, 55.6\% were married, $88.9 \%$ had education for less than eight years, and $66.7 \%$ were unemployed. It was determined that of the women with completed treatment, $50.0 \%$ were aged fifty years and over, $56.3 \%$ were married, $56.3 \%$ had education for less than eight years, and $68.7 \%$ were unemployed.

The social perception and interpretations that occurred at the stage of diagnosis of breast cancer

A medical approval is required to prove the medical presence of discovery of the state of disease an individual experiences as she realizes that something goes wrong on her body. A medical approval takes place with the stage of diagnosis. The reactions of the women with breast cancer to diagnosis were very different from each other. Some women argued that they considered the diagnosis and the illness normal and did not feel much about it.
"Nothing came to my mind. I said it was meant to happen. I didn't think about it. I didn't want my children to be sad about it." (The First Group - SG).

"I immediately thought about the operation" (The First Group - NB).

"When I first learnt about it, I didn't do anything. I said it could happen. Diabetes or that (cancer), there's not much of a difference. I said God gave it to me." (The First Group - SY).

"I was sad, really very sad. I would not see my grandchild anymore. I was considerably worn out, but I bounced back...” (The First Group - GS).

"Nothing came to my mind. I said it was meant to happen. I didn't want my children to be sad about it." (The First Group - SG).

The medical discovery of the state of illness an individual experiences on her body also involves the social content of the disease. The social interpretation of the cause of the disease (with the content of acceptance) underlies the content concerned. In this context, the women whose breast cancer treatment had been completed stated that when they first learned that they had breast cancer, they experienced such reactions as rebellion, anger, and intensive sorrow. Later on, regarding the cause of cancer, it was seen that the women interpreted the various negative events and stress they had experienced as 'the cause of cancer'.

“...My mother is 67 years old, and my aunt is 75 years old. She also undergoes mammography. It first broke out in me. Why?..." (The Second Group - GA).

"....I used to have a very stressful life. My upbringing from the past and from the family was much disciplined. That is, I was told 'Don't talk to or do anything with men'. Well, they have resulted in this..." (The Second Group - KO).

“...there occurred a swelling in my left breast.... I went to a general surgeon... The general surgeon looked at it and said 'You should have an operation at the soonest time'... Meanwhile, there was also a young female doctor there... I asked her too: 'What is this mass, Ms. Doctor?' 'Nothing but cancer' she replied. I felt dizzy...." (The Second Group - GK).

The way the disease is learned by an individual is quite influential on the acceptance of the disease and its interpretation by the individual as well as its adaptation to her life via social construction. Those who experience a "tough" process of learning the disease interpret this as "the insensitivity" of medicine and medical employees.

"...For them, a patient will die, if you lose your life, but, for you, many things will be lost. That is to say, I find the doctor's sensitivity to me and my sensitivity to myself different..." (The Second Group - NF).

"...We showed it to a general surgeon. He told 'You might have breast cancer' to my face...” (The Second Group - GS).

The social perception and interpretations that occurred in the phases of the treatment stage of breast cancer

The fundamental phases of the treatment stage of breast cancer are surgical application, chemotherapy, and radiotherapy applications. The surgical application 
Gulengul Mermer et al

results in either the loss of breast called mastectomy or breast deformity.

i). Loss of Breast as a result of a Surgical Operation: Loss of breast is one of the most important issues regarding breast cancer. The female breast is interpreted as a crucial part of being a female; having a sexual identity, social roles, and a status in the society; and feeling oneself valuable/ adequate starting from the early stages of socialization. In breast cancer, however, the breast is both the place of origination of the disease and a symbol of getting rid of the disease. The women who had had mastectomy defined the loss of their body's wholeness as "feeling physically incomplete" and "having a flawed look."

The women in the first group who were still undergoing treatment especially highlighted the loss of completeness of their body and loss of their breasts.

"I was feeling incomplete. You know one side of mine doesn't exist. One side has a breast, but the other doesn't." (The First Group - HK).

"You look deformed. You say it is OK, but I have started to use bra.I put cotton in my bra. It is for the others' gaze." (The First Group - GO).

"...The image is impaired. You say that nothing will happen, but I have just started to use underwear. I put cotton..." (The First Group - GO).

“...I filled it with sponge and put it. Well, I didn't mind...” (The First Group - HS).

“...Well, what if one lacks a breast? Nothing...” (The First Group - HM).

The problems of appearance resulting from the lack of breast were generally expressed as the impairment of the body's wholeness by the women in the first group who were still at the treatment stage, and some women expressed that the absence of breast was not very important.

Although the disease threatened life, the loss of breast was regarded as a smaller loss by the women in the first group who were still undergoing breast cancer treatment, whereas the women with completed treatment in the second group experienced the gap of losing part of theirs that was of great importance for their physical images and sexual identities.

"...Finally, I had the operation. Of course, the breast was removed. Then, I went topsy-turvy...” (The Second Group - GD).

“...It was of course good for them, but the result was not good for me... Why did I lose it as a whole although I had realized it early? If it were internal organs in my body... you return to those days in front of the mirror... There is no tolerance for this...”(The Second Group - GA).

"...Before entering the operation, they said 'let's have a look at it. Maybe we won't remove it', but I said 'if necessary, remove it'" as I wanted to live. But then, I considerably regretted at the first moment after the operation... I used to be a very beautiful girl, and my breasts were very beautiful too..." (The Second Group - $A S)$.

"...He told me that they would consider my situation during the operation and decide on what was necessary there... I trusted my doctor very much. At that time, I said that they could remove both of my breasts..." (The
Second Group - $C B$ ).

Losing the breast cannot be accepted easily by the women with completed breast cancer treatment in the second group. Survival and going on life are good; however, lacking a breast and going on life indicate a hard stage. 'Taking life back in return for the sacrificed breast' turns out to be the social meaning of the loss of breast.

ii). Chemotherapy \& radiotherapy: The women still undergoing treatment often complained about chemotherapy, which caused a serious decline in the quality of life. They also complained about the side effects of chemotherapy. Nausea and vomiting were mentioned as the two most disturbing side effects.

"Nausea and vomiting are terrible. Alas, I didn't want anyone with me because I didn't want them to see me like that." (The First Group - HM).

"Oh really, I had never seen a poison-taste pill like that before. I had never seen a bitter taste like that before." (The First Group - NA).

The women in the first group argued that they had a rest on the following days of chemotherapy and paid special attention to their nutrition on those days.

"For instance, I go to bed for 1.5 to 2 hours during the day every day. That is enough for me. After chemotherapy too, I was going to bed." (The First Group - GO).

"...On its first day, I drank about a kilo of Ayran. I want to see neither Ayran nor water... I do lie. I neither eat anything nor drink water..." (The First Group - SY).

"... I cannot drink any other thing. I could never drink water. Never... Do you know how that water stank? You can't drink it. It stinks..." (The First Group - HM).

“...I do not eat or drink. I am continually lying.I know it, but my stomach doesn't accept it after chemotherapy. The food smells in the kitchen..." (The First Group - FS).

The social perception by the women in this group of the period when they underwent chemotherapy focuses on the side effects of chemotherapy. Such problems as the inability to eat, the inability to cook or having no palate underlie this social perception.

Chemotherapy constitutes a very tough dimension of the treatment stage of the disease of cancer and prevents an ill individual from participating in the everyday life at various degrees. The data about the women in the second group indicate such social perception and interpretations.

“...I swear I don't remember how many medicines I took, but I did so. This did not remain in my mind at all. Regarding the medicines, they told me 'Look! Your hair will shed'... I just want to get rid of this trouble ..."(The Second Group - AS).

“...because I was bad. I'm sorry to say that but I was continuously vomiting. My mother was coming and helping me with my toilet need in the room... I lost my physical control... I felt bad when I took the medicine..." (The Second Group - SK).

"...Despite this disease, except for its forcing me, I was very tired in chemotherapy and couldn't stand up..." (The Second Group - GS).

“...I am still controlling my body. My physical resistance is very low with the medicines and the treatment, but I am carrying on the same activity at the same speed as if my resistance never fell. I am receiving 
Social Perceptions of Breast Cancer by Women Undergoing or Having Completed Treatment: a Qualitative Study

support for the housework. However, it couldn't make me turn in to myself. I didn't allow it and nor my friends/ relatives ..." (The Second Group - NF).

It was seen that the impairment of the stable relationship between an individual and her body underlay the social perception and interpretations of chemotherapy by the women in the second group at the time after the treatment stage had been over. The problems in the form of failure to meet her simplest demands in everyday life such as eating, walking, and going to the toilet and failure to fulfill her daily responsibilities constituted the sources of the social interpretations concerned. Therefore, although chemotherapy is a treatment stage, most patients match it with the disease of cancer itself and interpret that 'the end of chemotherapy is the beginning of the process of recovery'.

iii). Hair Loss: One of the clearest side effects of the medicines prescribed at the stage of chemotherapy is the shedding of hair, eyebrows, and eyelashes. Even though the loss of hair is a situation which is difficult to accept for ill individuals as the loss of breast, variations are seen between the groups.

"I wasn't afraid of chemotherapy. But, look, I have no hair left." (The First Group - NA).

"Then, I also had my hair shaved. It doesn't shed anymore. It stopped. But, now I don't have much hair." (The First Group - GO).

"They shed in the bath, when I wash my hair. There was a huge amount of hair in my hand once." (The First Group - G.O.).

“...It doesn't matter at all. Who cares? It is not important to lack hair. It is our health which is important..." (The First Group - SC).

Regarding the shedding of hair, the women with breast cancer who were still undergoing treatment thought that the shedding of hair was unimportant and temporary. Their main social interpretation was 'to get rid of the disease'.

The main social interpretation of the loss of hair by the women with completed breast cancer treatment in the second group was that the loss of hair was a very upsetting loss which was hard to overcome in spite of knowing that it was a side effect of the treatment of the disease.

“...First of all, I had my photo taken with my long hair. Our neighbor came with a machine to cut my hair. That day, I cried a lot ..." (The Second Group - GK).

"...because each time I put my hand, it came to my hand. I was demoralized. Well, it affected more than the breast..." (The Second Group - GS).

"...I entered the bathroom to take a shower. Suddenly, my hair came to my hand. It was the 13th day of the second chemotherapy... That day, I cried a lot..." (The Second Group - NV).

In both groups, hair loss is interpreted as a "loss", as with the loss of breast. Nevertheless, the difficulty in hiding it from the social environment and in its being tolerated by the individual further stands out since 'the hair' is a 'visible' element of the physical image in the context of the interpretation in the second group.

The social perception and interpretations of support by the family and the social environment
Cancer is a disease which affects the relationships of an ill individual with her family and the social environment at a level which is as high as its effect on the body of the individual. The participants told that during the treatment, their children, siblings, relatives, etc. supported them. They all argued that this social support was very important and that their acquaintances and neighbors, too, were important supporters.

"Sometimes when people approach you, they pity you. 'How come you have cancer?' They say, 'but don't worry, you'll get better.' Young people are more conscious of it: 'now everyone has cancer, you'll recover and it will be over. We try to encourage ourselves like that" (The First Group - GO).

“.. Attention is really important.I have a six-year-old grandchild, but I cannot describe how he is interested in me. Well, I can say that his interest in me is more than that of the elderly...." (The First Group - HM).

"...While I was receiving the chemotherapy medicine, my son was bringing me. I needed a toilet. The son was taking me to the toilet together with the machine..." (The First Group - HO).

“...My husband supported a lot. Since he had earlier been ill very much and known some things, he extended support to me too..." (The First Group - GO).

"... I said that if my husband did not like, it was his problem. I didn't mind. I still don't mind either...” (The First Group - HM).

"...I have got a neighbor with whom I talk to sincerely. There is an old aunt of mine. She loves me very much. She both pities very much and is upset..." (The First Group - GO).

The women still undergoing breast cancer treatment in the first group had some social perception and interpretation that the social support with which they were provided by their family and friends/relatives was of crucial importance. Accepting that one has been caught by cancer is difficult for an individual and the same applies to the spouse and the children. For the women with completed breast cancer treatment in the second group, the positive course of the process in which the husband learns the disease and then supports the ill woman is described as a very positive situation for the entire disease process by the women; furthermore, it is interpreted to help eliminate the existing problems in a marriage. However, if problems exist in a marriage, the process of supporting cannot be experienced and the following meaning is created: 'cancer worsens the marriage and problems'.

“...My husband and my children also supported a lot. My husband helped in every matter. He cooked and cleaned... He retired..." (The Second Group - GS).

"...I never supposed that my husband would support so much. He was dependent on me like a child. However, he has changed a lot. We used to have problems between each other and they all ended..." (The Second Group - SK).

“...Of course, home was also affected by it... My children were considerably affected too... My elder son saw a woman in every form which he shouldn't have seen, i.e. without breasts and hair... My younger son was 3 years old then and enabled me to hold on to life..." (The Second Group - AS). 
“...I was also personally offended by my husband. So, I didn't tell him. He would learn at any rate. For me, nothing would differ whether he learned it three or five days earlier..." (The Second Group - NF).

"...A few months passed and I was caught by it. It means that they are also talking about me now. However, I don't go to the meetings anymore... Why don't I go? Because they look. They say 'You have considerably gained weight', and 'You have got shorter too'... 'But you know my disease and what I have suffered' I say. I am demoralized..." (The Second Group - GK).

Relationships with the social environment may vary according to the qualities of the environment concerned and its communication with the patient. While patients maintain their relationships with the social environment which is conscious of, and extends support regarding, the disease of cancer, they may decide not to carry on their relationships with those who are afraid as they consider cancer a contagious disease. The patients interpret this as 'being together with those who cheer them up in the disease period' or 'staying away from those who demoralize'.

The social perception and interpretations of support and therapy groups

The participants argued that being together with different women who were going through the same processes was very comforting during the treatment process. During the focus group interviews, the participants argued that there was a need for "breast cancer support groups" at the hospital and that it would be helpful to join such a group.

"I didn't participate in such groups, but I want to do so. I would like to give emotional support to my friend." (The First Group - GO).

"Sure. All in all you have the same illness. Of course, we were talking and chatting about it. You understand what she's been through and she understands your problems." (The First Group - HM).

"...We never joined, but it would have been very good...” (The First Group - GT).

"...Of course, you become friends with the same fate...” (The First Group - SC).

“...We were like a family...” (The First Group - GS).

The women in the first group stated that they had required "breast cancer support groups" throughout their treatment processes and considered it useful to join such a group. They had some social perception that being together with different people who experienced the same disease would comfort them. The women in the second group stated that they had had a greater need for support groups.

“...I saw a support group at the hospital. We do share, but there are also people who don't want. A friend of mine did not want to talk at all..." (The Second Group - SK).

"I always heard about the associations. I considered joining so as to learn the things I didn't know. 'You change something and create a difference'I said..." (The Second Group - NF).

“...Cancer had both pros and cons in my life... Its advantage was my foundation of this association... I say 'My breast went, but the eyes of my heart opened'.
Its contributions to me were helping people, sharing something, and informing..." (The Second Group - CB).

The therapy and support groups with different qualities help patients at various levels in the context of their different qualities. For women, the main social meaning of support groups is to share a similar disease process via similar physical and social losses and overcome the disease.

\section{Discussion}

In this study, where it was aimed to determine the social perception and social interpretations of breast cancer by the women diagnosed with breast cancer in the treatment process and in the post-treatment periods, the perception by the participants in the study at the stages of diagnosis and treatment of breast cancer and their social perception and interpretations of the support by their families and social environments and of the support/therapy support groups during these processes were evaluated.

By the early $20^{\text {th }}$ century, the disease had appeared a case investigated with a medical understanding and research techniques. The reinforcement of the relationship between the disease and the social environment in the 20th century caused the connection of this relationship with 'the social' to stand out. The connection of the disease with the social indicates that it contains social factors as much as medical factors. This study aimed to determine social perception and interpretations - one of the social factors contained in the process of the disease of breast cancer. Findings were obtained regarding the social perception and interpretations of breast cancer by the patients within the four basic steps including the diagnosis and treatment processes of the disease of breast cancer.

The four basic processes whereby the social perception and interpretations of the disease of cancer were determined, i.e. the diagnosis/treatment of breast cancer; the treatment including the phases of loss of breast, chemotherapy, and hair loss; support by the family and the social environment; and support/therapy groups, were evaluated.

It is seen that there are variations in the social perception and interpretations of the diagnosis/treatment stage of breast cancer by the women still undergoing treatment and the women with completed treatment. Some of them had interpretations towards accepting the disease, whereas some of them had interpretations including such emotions as rebellion and anger. The content of the interpretations concerned may be far more negative among the women who "suddenly learn" their disease. The basic interpretations occurring at this stage are based on finding a reason for cancer. Most women developed a form of interpretation that regarded the problems in their lives as the reason for cancer.

The social perception and interpretations of losses stand out at the treatment stage of the disease. The loss of breast is the first important loss and has two different interpretations: the loss of breast was perceived and interpreted as a minor loss by the women still undergoing treatment, while it was interpreted as the loss of a crucial element of the physical image and sexual identity by the 
women with completed treatment.

The interpretation of hair/eyelash loss has some content similar to that of the loss of breast. For some of the women, it is a loss in order to survive, while, for a group of women, it is a loss which is very upsetting and hard to overcome.

The social perception and interpretations of chemotherapy by the women were related to the side effects of chemotherapy and the losses of physical control that prevented them from participating in the everyday life. The basic social interpretation concerning this period is that the end of chemotherapy is the beginning of the process of recovery.

Women with breast cancer have some social perception and interpretation that the family and social support are of great importance. The women with completed treatment also interpret this process as enabling to eliminate the problems existing in the marriage. This process appears with positive interpretations among those who were supported by their friends/relatives, whereas negative social perception and interpretations were encountered among those who were not supported.

The social perception and interpretations of support and therapy groups vary depending on the participation of women in these groups. Those who have not joined these groups yet have a positive interpretation that the groups will be useful. Nevertheless, the positive content about support by the groups in the social interpretations by those who joined further stands out.

Likewise, the data in the study by Gultekin in the field of medicine and in the study by Nazlı in the field of medical sociology were parallel to each other. Both studies mainly attached importance to the social dimension of the disease and stressed that the disease was not only a medical but also a social case.

Limitations of the Study: The application of different methods to the groups is a limitation in this study. It is recommended to apply the same method to the groups for equivalence in terms of number and technique.

\section{Acknowledgements}

We thank all the patients who graciously gave up their time to take part in this study

\section{References}

Bakos AD, Hutson SP, Loud JT, et al (2008). BRCA mutationnegative women from hereditary breast and ovarian cancer families: a qualitative study of the BRCA-negative experience. Health Expect, 11, 220-31.

Chung LK, Cimprich B, Janz NK, Bills-Wisneski SM (2009). Breast cancer survivorship program: testing for crosscultural relevance. Cancer Nursing, 32, 236-45.

Ferrell BR, Grant MM, Funk B, Otis- Green S, Garcia N (1997). Quality of life in breast cancer survivors as identified by focus groups. Psycho-Oncol, 6, 13-23.

Fouladi N, Ali-Mohammadi H, Pourfarzi F, Homaunfar N (2014). Exploratory study of factors affecting continuity of cancer care: Iranian Women's perceptions. Asian Pac J Cancer Prev, 15, 133-37.

Gall LT, Cornblat WM (2002). Breast cancer survivors give voice: a qualitative analysis of spiritual factors in long-term adjustment. Psycho Oncol, 11, 524-35.

Gonzalez LO, Lengacher CA (2007). Coping with breast cancer: a qualitative analysis of reflective journals. Issues Ment Health Nursing, 28, 489-510.

Guler C, Akın L (2006). Basic information on public health. the 1 st edition, publications by hacettepe university, Ankara.

Gultekin N (2009). Women's perception of breast cancer: a focus group study, department of midwifery, institute of health sciences, ege university, and unpublished master's thesis. Izmir.

Gurm BK, Stephen J, MacKenzie G, et al (2008). Understanding Canadian punjabi-speaking South Asian women's experience of breast cancer: a qualitative study. Int J Nursing Studies, 45, 266-76.

Henderson PD, Gore SV, Davis BL, Condon EH (2003). African American women coping with breast cancer: a qualitative analysis. Oncol Nursing Forum, 30, 641-47.

Howard A, Balneaves H, Bottorf J (2007). Ethnocultural women's experiences of breast cancer: a qualitative meta study. Cancer Nursing, 30, 27-35.

Karbani G, Lim JN, Hewison J, et al (2011). Culture, attitude and knowledge about breast cancer and preventive measures: a qualitative study of South Asian breast cancer patients in the UK. Asian Pac J Cancer Prev, 12, 1619-26.

Kim IR, Cho JH, Choi EK, et al (2012). Perception, attitudes, preparedness and experience of chemotherapy-induced alopecia among breast cancer patients: a qualitative study. Asian Pac J Cancer Prev, 13, 1383-88.

Lamyian M, Hydarnia A, Ahmadi F, Faghihzadeh S, AguilarVafaie ME (2007). Barriers to and factors facilitating breast cancer screening among Iranian women: a qualitative study. East Mediterr Health J, 13, 1160-9.

Loerzel VW, McNees P, Powel LL, Su X, Meneses K (2008). Quality of life in older women with early-stage breast cancer in the first year of survivorship. Oncol Nursing Forum, 35, 924-32.

Mellon S, Berry-Bobovski L, Gold R, Levin N, Tainsky MA (2007). Concerns and recommendations regarding inherited cancer risk: the perspectives of survivors and female relatives. J Cancer Educat, 22, 168-73.

Minnesota International Health Volunteers, (2006). Breast cancer in minnesota's somali community: focus group findings. (Online), www.mihv.nonprofitoffice.com, Accessed November 10, 2014.

Nazlı A (2008). Disease and the social construction of the body: a case study of breast cancer, guven bookst. Izmir.

Oxlad M, Wade TD, Hallsworth L, Koczwara B (2008). 'I'm living with a chronic illness, not... dying with cancer': a qualitative study of Australian women's self-identified concerns and needs following primary treatment for breast cancer. Eur J Cancer Care, 17, 157-66.

Peek EM, Sayad VJ, Markwart R (2007). Fear, fatalism and breast cancer screening in low-income African-American women: the role of clinicians and the health care system. $J$ Gen Intern Med, 23, 1847-53.

Rastad H, Khanjani N, Khandani BK (2012). Causes of delay in seeking treatment in patients with breast cancer in Iran: a qualitative content analysis study. Asia Pac J Cancer Prev, 13, 4511-5.

Rees CE, Bath PA (2001). Information-seeking behaviors of women with breast cancer. Oncol Nurs Forum, 28, 899-907.

Strauss AL (2003). Qualitative analysis for social scientists, cambridge university press, UK.

Strauss AL, Corbin JM (1998). Basics of qualitative researches techniques and procedures for developing grounded theory. sage pub, London. 
Gulengul Mermer et al

Tuncer AM (2007). Cancer control in Turkey. publications by the ministry of health. publication number: 707, Ankara.

Webb B (2002). Using focus groups as a research method: a personal experience. $J$ Nurs Management, 9660429.

WHO (2015). Breast cancer: prevention and control. http://www. who.int/cancer/detection/ breastcancer/en/index 3. html. date of access: April 17, 2015. 